\title{
RISCOS DE CONFORMIDADE TRIBUTÁRIA: UM ESTUDO DE CASO NO ESTADO DE SÃO PAULO
}

\section{RISK OF TAX COMPLIANCE: A CASE STUDY IN THE STATE OF SÃO PAULO}

\author{
Roberto Kazuo Miyoshi ${ }^{a}$; Sílvio Hiroshi Nakao ${ }^{b}$ \\ ${ }^{a}$ Agente Fiscal de Rendas da Secretaria da Fazenda do Estado de São Paulo \\ Mestre em Controladoria e Contabilidade pela Universidade de São Paulo - USP. \\ Ribeirão Preto, SP-Brasil; E-mail: afrkazuo@gmail.com \\ ${ }^{b}$ Professor Doutor do Departamento de Contabilidade da Faculdade de Economia, Administração e \\ Contabilidade de Ribeirão Preto da Universidade de São Paulo \\ Doutor e Mestre em Controladoria e Contabilidade pela Universidade de São Paulo - USP. \\ Ribeirão Preto, SP-Brasil; E-mail: shnakao@usp.br
}

Resumo

Esta pesquisa fornece um estudo empírico a respeito de fatores que afetam os riscos relacionados à conformidade tributária. Para obter dados em profundidade com vistas a alcançar o objetivo da pesquisa, utilizou-se de um estudo de caso de uma indústria que implantou um gerenciamento de riscos tributários concernentes ao ICMS do Estado de São Paulo, até então inexistente. Recorrendo-se à metodologia sugerida pelo COSO para o gerenciamento de riscos, identificou-se seus componentes, os riscos e os fatores que os desencadeiam, as atividades de controle e as respostas aos riscos implantadas que causam impacto nos custos de conformidade tributária. Avaliou-se as metodologias de natureza quantitativa e qualitativa de mensuração de riscos, e foram encontrados pontos fracos e fortes em ambas as metodologias. Observou-se que a percepção da empresa sobre os riscos tributários não possui completa aderência com a avaliação quantitativa. Os recursos humanos foram identificados como o fator de risco mais relevante dentro do ambiente da empresa investigada. Verificou-se também que ao estabelecer as atividades de controle e resposta aos riscos tributários, incorre-se em uma elevação nos custos de conformidade tributária, mas este impacto é mitigado pela redução à exposição dos riscos tributários.

Palavras-chave: Riscos de conformidade tributária; tributação; custos de conformidade tributária. .

\begin{abstract}
This research provides an empirical investigation about factors that affect the risks related to tax conformity. To obtain data in depth in order to achieve the objective of the present research, it was used a case study of an industry that has implemented a management of tax risks concerning ICMS of São Paulo state - Brazil, which didn't exist until then. Using the methodology suggested by COSO for risk management, its components as well as the risks and factors that trigger them and the activities of control and response to tax risks that impact on the tax compliance costs were identified. Quantitative and qualitative methodologies of risk measurement were evaluated and strengths and weaknesses were found in both methodologies. It was observed that the perception of the company on the tax risks has no complete adherence with the quantitative evaluation. The human resources were identified as being the most relevant risk factor within the environment of the investigated company. It was also found that while establishing the control activities and response to tax risks, the company incurs in an increasing of tax compliance costs, but this impact is mitigated by the reduction of the exposure of tax risks.
\end{abstract}

Keywords: Tax compliance risks; taxation; compliance cost of taxation. 


\section{INTRODUÇÃO}

O pagamento de tributos é a transferência de uma parcela de riqueza gerada pela sociedade ao Estado, representando parte do custo de um sistema tributário. Todo e qualquer sistema tributário, além de determinar o pagamento de tributo, impõe uma série de obrigações a serem cumpridas pelo contribuinte, seja ele pessoa física ou jurídica.

Representam tais obrigações a entrega de declarações ao Fisco, o correto cálculo do tributo a ser recolhido, a retenção em nome de terceiros, o registro de todos os documentos fiscais nos livros pertinentes, a custódia de documentos relacionados ao tributo, o registro da empresa e de suas filiais nos órgãos fiscais, etc.

Os gastos com a realização destas tarefas são chamados de custos de conformidade tributária, representando não apenas os recursos utilizados para a satisfação de obrigações tributárias acessórias, mas também os despendidos em assuntos relacionados à tributação (GODWIN, 1978).

Os riscos tributários, definidos como todos os riscos que podem influenciar um resultado tributário inesperado em função da desconformidade tributária, geralmente não têm sido bem compreendidos ou transparentes para todos os agentes envolvidos em uma empresa. A falta de percepção da complexidade da legislação tributária e de sua importância por parte da administração pode ter consequências severas para a empresa (NEUBIG; SANGHA, 2004).

A desconformidade à legislação tributária não ocorre apenas com o descumprimento das obrigações tributárias acessórias, mas pode ocorrer também com a obrigação tributária principal quando há o pagamento de tributo em valor menor do que o devido, normalmente por interpretações equivocadas quanto à aplicação da base de cálculo e/ou alíquota.

Estão previstas diversas penalidades por parte do fisco pelo não cumprimento de sua legislação e que podem impactar o resultado de forma significativa, podendo até inviabilizar a continuidade das operações de uma entidade.

A sua incidência pode ser minimizada através de um gerenciamento de riscos, reduzindo a probabilidade de um impacto negativo no resultado da empresa. Entretanto, sua gestão é um processo complexo devido a inúmeras variáveis de difícil quantificação e à mensuração de sua influência nos riscos. Desta forma, a identificação e priorização dos riscos advindos de diversas fontes e seu inter-relacionamento é de extrema importância para a sua gestão e consequente mitigação de seus impactos (SVENSSON, 2004).

Considerando que "o objetivo básico da Contabilidade é o fornecimento de informações econômicas para os vários usuários, de forma que propiciem decisões racionais" (IUDÍCIBUS, 2009 , p. 7), o conhecimento científico a respeito dos riscos tributários pode melhorar a abrangência da descrição dos fenômenos relacionados, permitir o desenvolvimento de melhores práticas de gerenciamento de riscos e custos tributários, além de proporcionar o desenvolvimento de políticas públicas para o aumento da competitividade das empresas em atividade no Brasil. Desta forma, quais são os fatores que cercam os riscos relacionados à conformidade tributária? Esta análise permite que sejam identificados os eventos que podem gerar riscos tributários, bem como os fatores que os desencadeiam.

A percepção da probabilidade e do impacto no resultado, representados pelos riscos de compliance tributária, são importantes para o desenvolvimento de uma resposta a sua ocorrência e do delineamento de seu monitoramento e gerenciamento, permitindo traçar estratégias para atacar os fatores de risco. Portanto, tem-se como objetivo descrever empiricamente por meio de 
estudo de caso o processo de gerenciamento dos riscos de conformidade tributária, identificar os fatores de risco relacionados e avaliar os métodos de mensuração desses riscos.

Preliminarmente, foram analisados os processos e procedimentos levados a efeito pela empresa objeto do estudo de caso que possuem relação com o cumprimento da legislação tributária. Dessa análise, foram identificados e avaliados os riscos e suas metodologias de avaliação relacionadas à conformidade tributária.

A Empresa A, objeto do estudo de caso, implantou o processo de gerenciamento de riscos tributários em 2003, motivada por uma multa tributária lavrada contra si. Por esse motivo, os processos e procedimentos analisados referem-se aos realizados até meados do exercício de 2003, em comparação com aqueles vigentes em 2010.

A avaliação dos riscos foi qualitativa, em função da probabilidade de ser autuada pelo Fisco Estadual e de seu impacto no resultado da empresa, e quantitativa, através da utilização de média aritmética dos riscos tributários e de seu Value at Risk (VaR).

Quanto aos riscos tributários, o escopo limitou-se à legislação tributária paulista, relativamente ao Imposto sobre Operações Relativas à Circulação de Mercadorias e Sobre Prestações de Serviços de Transporte Interestadual e Intermunicipal e de Comunicação (ICMS). É importante observar que os resultados apresentados nesta pesquisa são específicos para os fatos, situações e contextos observados na empresa objeto de estudo. A metodologia escolhida, denominada de estudo de caso, apresenta limitações para generalizações ou extrapolações.

\section{REFERENCIAL TEÓRICO}

\subsection{Relação de agência entre fisco e contribuinte}

A literatura tem tratado a relação de agência, com os acionistas no papel de principal e os gerentes como os agentes. Entretanto, o modelo da relação de agência não é rígido, podendo ser caracterizado também pela relação fisco x administrador (MARTINEZ, 1998).

Reinganum e Wilde (1985) utilizaram-se do modelo principal-agente para estudar as políticas de auditoria tributária, realizada pela Internal Revenue Service (IRS), em função das declarações apresentadas pelos contribuintes do imposto de renda.

Neste contexto o Estado, atuando como principal, deseja saber quais são as operações realizadas pela empresa e o seu resultado, para cobrar o tributo devido; e o agente procura minimizar o pagamento de tributos e declarar o mínimo de informações possíveis a respeito de seus negócios, seja de forma lícita ou ilícita. Esta situação é tipicamente denominada de conflito de agência, onde o agente assume um comportamento oportunista visando maximizar o seu bem-estar, em detrimento do principal (SAITO; SILVEIRA, 2008). Para diminuir esta assimetria, o fisco estabelece diversas obrigações a serem cumpridas pela empresa, as chamadas obrigações tributárias acessórias.

Em razão da complexidade da legislação tributária e do volume de obrigações acessórias a serem cumpridas, as empresas despendem recursos consideráveis para a questão, os quais são definidos como custos de conformidade tributária. 


\subsection{Custos de conformidade tributária}

Para uma empresa, o custo da tributação pode ser dividido basicamente em três: os custos de conformidade tributária; os tributos recolhidos aos cofres públicos; e os custos de distorção na economia provocados pelos tributos.

Os custos de conformidade tributária representam todos aqueles custos incorridos por contribuintes, ou terceiros, em satisfazer todos os requisitos e obrigações impostas por um sistema tributário. Incluem-se nesta definição o custo de aquisição de conhecimento suficiente para satisfazer todas as determinações tributárias, registrar e guardar os recibos e outros documentos necessários para o preenchimento de declarações fiscais; o pagamento de profissionais especializados em tributação e a remuneração de funcionários que tratam de questões tributárias; custos incidentais como postagem, telefone e viagens para encontrar-se com os consultores ou com a repartição pública tributária (SANDFORD; GODWIN; HARDWICK, 1989).

Segue quadro com os artigos localizados, com um breve relato de seus estudos.

\begin{tabular}{|c|c|}
\hline Autor(es) & Resumo dos trabalhos realizados \\
\hline $\begin{array}{l}\text { Slemrod e } \\
\text { Blumenthal } \\
\quad(1996)\end{array}$ & $\begin{array}{l}\text { Conduziram estudos com aproximadamente } 1.300 \text { grandes empresas americanas em } 1992 \text { e } \\
\text { detectaram que os maiores custos atribuídos a questões tributárias estaduais são consequência } \\
\text { da não uniformidade dos sistemas tributários estaduais, e que a reforma tributária levada a } \\
\text { efeito em } 1986 \text { aumentou os custos de conformidade. }\end{array}$ \\
\hline Kaplow (1996) & $\begin{array}{l}\text { O governo possui à sua disposição diversas ferramentas para a conformidade: declarações } \\
\text { de informações econômico-fiscais, auditoria, penalidades; complexos sistemas tributários } \\
\text { impõem altos custos de conformidade. }\end{array}$ \\
\hline $\begin{array}{l}\text { Bertolucci } \\
\quad(2001)\end{array}$ & $\begin{array}{l}\text { Pesquisa de custos de conformidade tributária realizada em companhias de capital aberto. } \\
\mathrm{Na} \text { média, tais custos representaram } 0,32 \% \text { do faturamento anual. Constatou-se a forte } \\
\text { regressividade dos custos, e que os recursos internos representam aproximadamente } 80 \% \text {; as } \\
\text { atividades de controladoria, jurídico e informática representam } 33,8 \% \text { do custo total. }\end{array}$ \\
\hline $\begin{array}{l}\text { Slemrod e } \\
\text { Venkatesh } \\
(2002)\end{array}$ & $\begin{array}{l}\text { Conduziram estudos de conformidade tributária em média e grandes empresas, cujo relatório } \\
\text { foi apresentado ao IRS LMSB Division. Os resultados foram a regressividade dos custos em } \\
\text { relação ao tamanho da empresa. A comparação foi realizada em função do valor dos ativos, e } \\
\text { não do faturamento auferido. }\end{array}$ \\
\hline $\begin{array}{l}\text { Evans e Tran- } \\
\text { Nam (2002) }\end{array}$ & $\begin{array}{l}\text { Pesquisa realizada na Austrália constatou que, para as grandes empresas, o maior componente } \\
\text { dos custos serão os custos internos, pois deverá haver dispêndio em relação a cursos de } \\
\text { treinamento, o maior tempo despendido pelo pessoal para a preparação das declarações e } \\
\text { a ocorrência de possíveis incidentes até familiarizarem-se com a nova metodologia; para as } \\
\text { pequenas e médias empresas, o maior componente dos custos será da contratação de consultores } \\
\text { externos com o conhecimento desta nova metodologia. }\end{array}$ \\
\hline Kopezuk (2006) & $\begin{array}{l}\text { A complexidade de uma legislação tributária aumenta a probabilidade da ocorrência de erros } \\
\text { no cálculo dos tributos e, consequentemente, os custos da tributação. }\end{array}$ \\
\hline $\begin{array}{l}\text { Das-Gupta } \\
\text { (2006) }\end{array}$ & $\begin{array}{l}\text { Levantamento realizado na Índia, relativamente ao biênio } 2000-2001 \text {, em relação ao imposto } \\
\text { de renda, constatou-se que: o custo de conformidade tributária é da ordem de } 0,21 \% \text { das } \\
\text { receitas; } 70 \% \text { das empresas pesquisadas utilizam-se de consultor tributário externo devido à } \\
\text { complexidade do sistema tributário e da alta frequência de sua alteração. }\end{array}$ \\
\hline
\end{tabular}

Quadro 1: Artigos relacionados com custos de conformidade tributária

No Brasil, os custos de conformidade tributária são representados, em sua maioria, pelos recursos empregados para a satisfação das obrigações tributárias acessórias, cujo descumprimento nos ditames da legislação aplicável pode transformar-se em uma autuação fiscal. 
Se a empresa não realizar o pagamento do auto de infração, além de sofrer processo de execução fiscal, os seus sócios, diretores ou gerentes correrão o risco de sofrer processo por crime de sonegação fiscal, tendo que contratar advogados para defendê-los. Assim, percebe-se que as consequências da materialização de um risco tributário em autuação fiscal podem não ficar limitadas à perda de parte do patrimônio de uma entidade, o que denota a importância da existência de um gerenciamento eficiente dos riscos tributários.

\subsection{Controles internos}

Controles internos são, conforme Almeida (1996, p. 50), "o conjunto de procedimentos, métodos ou rotinas com os objetivos de proteger os ativos, produzir dados contábeis confiáveis e ajudar a administração na condução ordenada dos negócios da empresa".

Eles manifestam-se de diversas formas, desde um simples procedimento operacional para a elaboração de processos, até a revisão de avaliações de desempenho e que envolvem os mais diversos níveis administrativos por um período de tempo significativo (MERCHANT; OTLEY, 2007).

O Committee of Sponsoring Organization of the Treadway Commission (COSO) faz a seguinte definição de controle interno (COSO, 1992, tradução livre): Controle interno é amplamente definido como um processo, realizado pela diretoria de uma entidade, gestores e outras pessoas, projetado para conferir uma razoável segurança do cumprimento dos objetivos traçados, nas seguintes categorias:

- efetividade e eficiência das operações;

- confiabilidade das demonstrações financeiras;

- conformidade com as leis e normas vigentes. ${ }^{1}$

Desta definição, percebe-se que a sua finalidade é a de que os objetivos traçados pela empresa sejam atingidos com razoável segurança.

A análise dos controles internos não pode ser dissociada da do risco. A existência de qualquer atividade ou procedimento abre a possibilidade da ocorrência de risco em sua execução. No contexto de governança corporativa, a intensidade da interconexão entre risco e controle interno levou a uma redefinição deste, de controle interno para gerenciamento de riscos (SPIRA; PAGE, 2003).

Em função das diversas crises ocorridas em meados de 1990, houve um movimento crescente, por parte das organizações, de que o gerenciamento de riscos deve ser relacionado de forma explícita com os objetivos organizacionais (POWER, 2009).

\subsection{Gerenciamento de riscos}

Toda empresa enfrenta incertezas na condução de suas operações que podem interferir

$1 \quad$ Internal control is broadly defined as a process, effected by an entity's board of directors, management and other personnel, designed to provide reasonable assurance regarding the achievement of objectives in the following categories:

1. Effectiveness and efficiency of operations.

2. Reliability of financial reporting.

3. Compliance with applicable laws and regulations 
na sua função principal, a geração de valor às partes interessadas. O gerenciamento de riscos corporativos permite à administração um tratamento eficaz quanto a estas incertezas e aos riscos a elas inerentes.

O conceito de risco está intimamente ligado ao retorno, através de uma correlação positiva entre a volatilidade dos resultados inesperados e a rentabilidade de um ativo ou passivo (JORION, 1999, p. 3).

Para a definição do risco, a probabilidade é um importante componente para a sua avaliação e determinação, podendo, os seus valores, serem estabelecidos de forma subjetiva ou objetiva (PENHA; PARISI, 2005).

No presente trabalho, será utilizada a definição de risco de COSO (2004a, p. 22), na qual o "risco é representado pela possibilidade de que um evento ocorrerá e afetará negativamente a realização dos objetivos".

A matriz de riscos é uma ferramenta que pode ser utilizada para uma mensuração qualitativa, onde a grandeza do risco é definida pela composição da probabilidade de sua ocorrência e o impacto financeiro no resultado (PAULO et al., 2007), sendo que para a avaliação quantitativa, normalmente utiliza-se de modelos probabilísticos ou não probabilísticos (COSO, 2004a). Não há um ambiente completamente desprovido de risco, mas estes podem ser evitados, reduzidos ou mitigados.

O gerenciamento de riscos engloba os conhecimentos, os métodos, os processos e procedimentos, as ações implementadas e melhoradas de forma contínua, visando a redução de prejuízos e o incremento dos benefícios na realização dos objetivos e metas estratégicas (BARALDI, 2010).

Compreende o conhecimento de suas causas e consequências, da percepção das oportunidades, através de procedimentos de identificação, quantificação, seleção, decisão, informação e comunicação, e aperfeiçoamento das respostas ao risco (BARALDI, 2010). O gerenciamento de riscos é um tema atual, sendo introduzido nas empresas, notadamente em suas práticas gerenciais, permitindo antecipar potenciais perdas.

Não foca apenas a organização como um todo, mas também áreas específicas tais como: risco de mercado, crédito, operação, publicação de demonstrações financeiras e de conformidade às leis e regulamentos (MERCHANT; OTLEY, 2007).

\subsection{Gerenciamento de riscos tributários}

O gerenciamento de riscos tributários não se confunde com planejamento tributário. Fabretti (2009, p. 8) define planejamento tributário, como "o estudo feito preventivamente, ou seja, antes da realização do fato administrativo, pesquisando-se seus efeitos jurídicos e econômicos e as alternativas legais menos onerosas". Depreende-se, portanto, que o planejamento tributário é a busca de dispositivos legais com a finalidade de minimizar o ônus tributário, focando essencialmente a economia tributária e o aumento do lucro.

Já o gerenciamento de riscos tributários está relacionado com os riscos em processos e procedimentos voltados ao correto cálculo do tributo a ser recolhido, bem como com a satisfação das demais obrigações tributárias acessórias. Portanto, para o presente trabalho, o risco está relacionado ao gerenciamento de riscos tributários, e não ao planejamento fiscal. Nesta linha, define-se risco tributário como "todos aqueles riscos que podem criar um resultado tributário inesperado" (NEUBIG; SANGHA, 2004, p. 114, tradução nossa). 
As atividades relacionadas à conformidade tributária transcendem o departamento de contabilidade, muito embora a maioria de seus procedimentos esteja concentrada nesta unidade.

A avaliação de riscos e as atividades de controle envolvem a identificação das formas em que a empresa pode incorrer em custos excessivos de conformidade e de tributação (GOODMAN, 2004), podendo ser desencadeadas por fatores externos, internos, ou ambos (ERNST \& YOUNG, 2008). Destarte, a complexidade da legislação tributária pode levar as empresas a interpretações diversas do Fisco, aumentando o risco tributário. Percebe-se, portanto, que os riscos à conformidade tributária podem prejudicar a eficiência de uma empresa e impactar o seu resultado de forma negativa.

A existência de um processo de gerenciamento de riscos tributários, independente e segregado daquele responsável pelos riscos corporativos, é uma tendência nas multinacionais americanas (WUNDER, 2009).

\subsection{COSO}

Em função dos diversos escândalos financeiros, notoriamente no final da década de 1980 e início de 1990, foi criado, nos Estados Unidos, o COSO², uma instituição privada, com a finalidade de estudar assuntos relacionados às demonstrações financeiras com vistas à sua melhoria e proporcionar às empresas um padrão seguro no monitoramento de seus sistemas de controles internos, resultando ao final, a publicação do Internal Control-Integrated Framework.

A obra supracitada teve como foco os sistemas de controle interno e buscou auxiliar as empresas a avaliar e aperfeiçoar tais sistemas (COSO, 2004a). Após a publicação, o gerenciamento de riscos tornou-se cada vez mais fonte de preocupação das empresas, que necessitavam de uma estratégia sólida, capaz de identificar, avaliar e administrar riscos (COSO, 2004a).

Em 2001, o COSO iniciou estudos voltados aos riscos, coincidindo com a ocorrência de novos escândalos de fraudes em empresas, principalmente nos Estados Unidos, gerando enormes prejuízos a acionistas, empregados e outras partes interessadas (COSO, 2004a).

Com o auxílio da PricewaterhouseCoopers, o COSO apresentou em 2004 o Enterprise Risk Management - Integrated Framework (Gerenciamento de Riscos Empresariais - Estrutura Integrada), adicionando aspectos estratégicos e de governança em relação ao Internal Control - Integrated Framework, focando a gestão de riscos (COSO, 2004a) e tornando-se em pouco tempo uma referência em relação a gerenciamento de riscos (POWER, 2009).

O COSO define gerenciamento de riscos corporativos como um processo contínuo conduzido por aqueles que trabalham em uma empresa em todos os níveis, utilizado para a definição de estratégias, identificação e administração de eventos que possam ocorrer e que poderão afetar a empresa, garantindo de forma razoável a persecução dos objetivos (COSO, 2004a). Partindo-se da missão estabelecida por uma organização, a sua administração delineia os planos principais, estabelece as estratégias e determina o alinhamento dos objetivos nos diversos níveis organizacionais (COSO, 2004a).

2 Formado por representantes da American Accounting Association, American Institute of Certified Public Accountants, Financial Executives International, The Association for Accountants and Financial Professionals in Business e Institute of Internal Auditors. 
O COSO (2004a) determina uma série de eventos para a gestão de processos em ambiente de controle, permitindo à administração levar em consideração os riscos aos quais uma empresa está exposta, além de avaliar os controles necessários para o gerenciamento dos riscos identificados. O ponto central do gerenciamento de riscos são os eventos que podem afetar os resultados estabelecidos pela organização. O modelo sugerido pelo COSO, não objetiva a eliminação total dos riscos, mas sim o seu controle em níveis aceitáveis conforme o apetite ao risco da empresa.

O processo de gerenciamento de riscos empresariais, preconizado pelo COSO (2004a), é constituído dos seguintes componentes:

- Ambiente interno - a direção estabelece uma política relacionada ao tratamento dos riscos, assim como os limites à tolerância ao risco;

- Fixação dos objetivos - o gerenciamento de riscos garante que a alta direção institua um processo para estabelecer os objetivos alinhados com a missão da organização;

- Identificação de eventos - os eventos em potencial devem ser identificados e classificados entre riscos e oportunidades;

- Avaliação de riscos - os riscos identificados são analisados, e mensurados o impacto e a probabilidade de sua ocorrência;

- Resposta a risco - a direção da empresa seleciona a resposta ao risco, podendo ser: evitar, aceitar, reduzir ou compartilhar;

- Atividades de controle - estabelecimento e implementação de políticas e procedimentos para assegurar a eficácia da resposta ao risco;

- Informações e comunicações - as informações consideradas relevantes são identificadas, colhidas e comunicadas de forma tempestiva;

- Monitoramento - a integridade do processo de gerenciamento de riscos é monitorada, e as correções necessárias são implementadas.

Infere-se que tais componentes contemplam toda a estrutura da empresa, possibilitando à administração ter um instrumento eficiente de apoio à tomada de decisão.

\section{METODOLOGIA}

Para examinar os fatores que cercam os riscos de conformidade tributária, foi selecionado o método de estudo de caso como estratégia de pesquisa. O seu emprego se justifica em função da escolha dos pesquisadores de se fazer a avaliação empírica desses riscos e de seus fatores em seus pormenores para se obter uma abordagem mais contingencial.

A presente pesquisa limita-se à legislação tributária paulista, focando, portanto, apenas os pontos de interesse desta legislação e os procedimentos que possam refletir no seu descumprimento. Realizou-se uma análise aprofundada dos processos e procedimentos de uma empresa que estão associados à tributação.

A Empresa A foi selecionada com base nas seguintes razões: apresenta uma estrutura clara, dedicada à conformidade tributária e incorre em riscos com a tributação, com ajustes em resposta ao risco; consentimento da administração, necessária para o levantamento de informações relativas à tributação e de processos e procedimentos internos, assim como 
dados financeiros; e acessibilidade à direção da empresa, ao consultor tributário externo e ao contabilista.

No ano de 2003, a Empresa A passou por uma auditoria fiscal por parte do Fisco paulista. As irregularidades constatadas resultaram em uma multa tributária que impactou significativamente o resultado daquele exercício, o que levou os diretores a contratar dois consultores tributários externos para a implantação de um gerenciamento de riscos tributários.

Em 2009, empreendeu diversas ações visando a adaptação e adequação dos processos e procedimentos para o manuseio da nota fiscal eletrônica - NFE. Em 2009, alguns de seus fornecedores já a emitiam, mas, para ela, a emissão tornou-se obrigatória apenas em 2010.

AEmpresa A é uma indústria nacional do ramo calçadista masculino, cujo regime jurídico é a de responsabilidade limitada. Atua no mercado há mais de 25 anos, possui aproximadamente 865 funcionários, sendo 800 no setor produtivo e 65 no setor administrativo, com capacidade produtiva de 7.000 pares/dia. Faturou, em 2010, aproximadamente R $\$ 90$ milhões e, além de atuar no mercado nacional, em todos os estados brasileiros, exporta para mais de 25 países.

O departamento de contabilidade absorve todas as questões tributárias levantadas pelos demais setores, sendo composto por um auxiliar contábil, dois auxiliares fiscais e um auxiliar de escritório, perfazendo um total de quatro funcionários chefiados pelo contabilista, sob a supervisão do consultor tributário externo. Desde 2009, a empresa está obrigada a realizar a escrituração contábil digital e enviá-la ao Sistema Público de Escrituração Digital (SPED), sendo que a partir de 2011, os lançamentos fiscais também deverão ser realizados neste formato, a Escrituração Fiscal Digital (EFD).

Em relação ao levantamento das demais informações ocorrido no período de dezembro de 2010 a julho de 2011, foram realizadas diversas entrevistas, tanto no escritório profissional do consultor tributário externo como na Empresa A, tendo o contabilista participado de algumas delas.

Utilizou-se de um roteiro de entrevistas com questionário semiestruturado sobre as obrigações tributárias paulistas a que está sujeita a Empresa A, sobre os processos e procedimentos relacionados à tributação paulista do ICMS ex-ante e ex-post à implantação do gerenciamento de riscos tributários, sobre os riscos ao cumprimento da legislação tributária paulista, o monitoramento dos processos e procedimentos. Também foram realizadas análises documentais, assim como observações in loco para corroborar e complementar os dados das entrevistas.

Neste estudo de caso, foram identificados e avaliados os eventos relacionados com riscos tributários. Esses eventos foram então classificados por fatores de risco, internos e externos. Os riscos de conformidade tributária foram então avaliados qualitativa e quantitativamente. Em seguida, foram examinadas as atividades de controle e resposta aos riscos efetuadas pela empresa e os procedimentos de monitoramento empregados. Os detalhes da metodologia são apresentados a seguir.

\subsection{Identificação e avaliação dos eventos}

Para a identificação e avaliação de riscos, normalmente utiliza-se inventário de eventos, workshop, realização de entrevistas e questionários (COSO, 2004b; STONEBURNER et al., 2001).

A realização de workshop demandaria a reunião de um pequeno grupo de funcionários oriundos de diversos setores e que realizam procedimentos ligados à tributação, o que não 
foi autorizado pelos diretores. Optou-se, portanto, pelo levantamento de inventário de eventos passados e a realização de entrevistas com o consultor tributário e com o contabilista em virtude de serem eles os que possuem maior contato com questões tributárias, além de serem responsáveis pela conferência, por amostragem, dos lançamentos realizados pelos demais setores junto ao sistema contábil/fiscal.

\subsubsection{Classificação dos eventos por fatores de risco}

Este trabalho adaptou a classificação do COSO (2004b) no processo de avaliação qualitativa de riscos, utilizando-se apenas dos seguintes fatores:

1. Fatores internos

- pessoal - capacidade dos empregados, erros e fraudes, saúde e segurança;

- $\quad$ processo - capacidade, design, execução;

- tecnologia - integridade e disponibilidade de dados, seleção de sistemas, desenvolvimento, alocação, manutenção

\section{Fatores externos}

- meio ambiente - emissões de poluentes, energia, desastres naturais;

- político - mudança de governo, legislação e regulamentos, política pública;

- tecnológico - interrupções, comércio eletrônico, dados externos, novas tecnologias.

Em relação ao fator de risco político presente na metodologia COSO, serão consideradas apenas as alterações na legislação tributária. Desta forma, para uma melhor inteligência, será utilizada a expressão tributação, definida por Crouhy, Galai e Mark (2004, p. 426) como um fator de risco externo.

Inseriu-se também, para o presente trabalho, o componente pessoal como fator de risco externo, uma vez que pessoas estranhas à Empresa A podem conspirar para causar-lhe prejuízo. Portanto, para o presente trabalho, foram selecionados os seguintes fatores de risco:

\section{Fatores internos -}

- pessoal (x1) - valores éticos inadequados, desatenção, falta de comprometimento, falta de capacitação e de capacidade profissional para o desempenho da função;

- processo (x2) - relacionado à eficácia e eficiência das atividades operacionais da empresa, composto de processos e procedimentos, inclusive os realizados por meio de sistemas de informações e que podem levar à desconformidade tributária;

- tecnologia/equipamentos (x3) - todos os equipamentos utilizados, tais como computadores, servidores de armazenamento e de impressão, roteadores via cabo e sem fio, conexão à internet que pode não funcionar conforme o esperado.

\section{Fatores externos}

- meio ambiente (y1) - chuvas, tempestades, raios, inundações, vendaval, etc.;

- pessoal (y2) - pessoas estranhas à organização, que conspiram para extrair vantagens ilícitas, e que podem levar à desconformidade tributária;

- tributação (y3) - mudanças na legislação tributária paulista, legislação federal ou estabelecimento de jurisprudência que tenham repercussões na legislação do 
ICMS, entendimento da fiscalização estadual divergente do da empresa;

- tecnologia (y4) - todo e qualquer problema ou alterações referente a padrões de sistemas, comunicações entre servidores externos, vírus de computador, etc.

\subsubsection{Critérios para avaliação qualitativa dos riscos tributários}

O COSO (2004b, p. 36) utiliza os critérios e escala do Quadro 2 para classificar a probabilidade de ocorrência de um evento.

\begin{tabular}{|c|c|c|}
\hline nível & descritor & probabilidade \\
\hline 1 & raro & muito baixa \\
\hline 2 & improvável & baixa \\
\hline 3 & possível & moderada \\
\hline 4 & provável & alta \\
\hline 5 & quase certo & muito alta \\
\hline
\end{tabular}

Quadro 2: Critérios para classificação de probabilidade da o corrência de risco (COSO, 2004b)

Fonte: COSO (2004b, p. 36)

Pelo fato de o presente trabalho se tratar de um estudo dos fatores de risco à desconformidade tributária paulista, a mensuração do impacto dos riscos teve como base as autuações e fiscalizações sofridas pela empresa a partir 1999, e a probabilidade foi relacionada à percepção da empresa na materialização do risco em multa tributária. Portanto, para análise do impacto dos riscos, foi utilizada a graduação sugerida pela COSO (2004b, p. 37), conforme Quadro 3:

\begin{tabular}{|c|c|}
\hline nível & impacto \\
\hline 1 & insignificante \\
\hline 2 & mínimo \\
\hline 3 & moderado \\
\hline 4 & alto \\
\hline 5 & catastrófico \\
\hline
\end{tabular}

Quadro 3: Graduação do impacto dos riscos conforme a metodologia sugerida pelo COSO (2004b)

Fonte: $\operatorname{COSO}(2004 b$, p. 37)

Ressalte-se que para esta classificação, foi considerada a percepção da Empresa A no final do exercício de 2010.

\subsubsection{Critérios para avaliação quantitativa dos riscos tributários}

Para a avaliação quantitativa dos riscos tributários, foram utilizados os dados de todas as entradas e saídas realizadas nos exercícios de 2003 e 2010. Os riscos identificados no Quadro 6 foram agrupados e classificados conforme as infrações descritas no artigo 527 do Regulamento do Imposto de Circulação de Mercadorias, Serviço de Transporte Intermunicipal e de Comunicação do Estado de São Paulo (RICMS/SP) $)^{3}$, e que também prescreve a penalidade pecuniária a ser imposta.

3 Este regulamento foi aprovado pelo decreto estadual n. 45.490/00. 
Os riscos identificados como a3, a4, b1, c4 e c9, do Quadro 6, não terão o seu risco calculado devido à ausência de dados suficientes e confiáveis. Não há previsão legal, na legislação tributária bandeirante, para penalizar diretamente a sua ocorrência. A tipificação desta irregularidade somente ocorre quando ocasiona a falta de pagamento do ICMS devido, seja pela ocorrência de saldo credor de caixa ou pela diferença de levantamento de estoque, sempre de forma indireta, e que pode ou não ter influência no correto cálculo do ICMS a ser recolhido.

Quanto aos riscos d1 e d2, do Quadro 6, não há como avaliar e quantificar a extensão dos dados eventualmente danificados, além de haver a possibilidade de reconstituição destes dados, se a empresa possuir os documentos físicos, mesmo após a notificação expedida pelo Fisco, bastando, para tanto, solicitar dilação do prazo de forma justificada.

Para a mensuração quantitativa dos riscos tributários, utilizou-se o cálculo de média dos riscos tributários (exercícios 2003 e 2010) e o Value at Risk(VaR). Este, apenas para o exercício de 2010. Para o cálculo do VaR, utilizou-se a seguinte fórmula (JORION, 1999, p. 87):

$$
\mathrm{VaR}=\mathrm{W}_{\mathrm{o}} \alpha \sigma \sqrt{ } \Delta \mathrm{t}
$$

Em relação aos riscos c1, c2, c7 e c8, considerou-se $\Delta \mathrm{t}$ como sendo os dias em que houve expediente na Empresa A, e que foi de 251 dias no ano de 2010; para o risco c11 considerou-se como o número de meses no ano (12); e para as variáveis c3, c5, c6 e c10, considerou-se o ano, então $\mathrm{t}=1$; o nível de confiança utilizado foi de $5 \%$, o que corresponde a $\alpha=1,65$; Jorion (1999) explica que $\sigma$ está expresso em percentuais de retorno, portanto, $\mathrm{W}_{\mathrm{o}} \sigma$ corresponde ao valor do desvio-padrão.

Para uma melhor análise do VaR da Empresa A, deve-se considerar a frequência das ocorrências dos riscos, contidos nas Tabelas 1, 2 e 3, assim como o cálculo do valor presente deste VaR, considerando o horizonte temporal como uma perpetuidade, através da seguinte fórmula:

$$
\text { Valor presente do } \mathrm{VaR}=\mathrm{VaR} / \mathrm{WACC}
$$

Para o cálculo do custo médio ponderado de capital (WACC), foi utilizada a seguinte fórmula:

$$
\mathrm{WACC}=\left(\operatorname{Ke} \times \mathrm{W}_{\mathrm{PL}}\right)+\left(\mathrm{Ki}(\text { após o IR }) \times \mathrm{W}_{\mathrm{P}}\right)
$$

onde Ke representa o custo de oportunidade de capital próprio, e $\mathrm{W}_{\mathrm{PL}}$ representa a proporção deste capital; Ki representa o custo explícito ao credor (antes ou após o Imposto de Renda de Pessoa Jurídica), e $\mathrm{W}_{\mathrm{P}}$ a proporção de capital de terceiros.

Para o cálculo do Ki, utilizou-se da seguinte fórmula:

$$
\mathrm{Ki}(\text { após IR })=\mathrm{Ki}(\text { antes do IR) } \mathrm{x}(1-\mathrm{IR})
$$

\subsection{Atividades de controle e resposta aos riscos}

As respostas ao risco podem ser divididas em quatro categorias (COSO, 2004b, p. 55):

- aceitar - nenhum procedimento é estabelecido para diminuir a probabilidade e o impacto do risco;

- compartilhar-redução do impacto e da probabilidade do risco através da transferência de parte do ônus do risco, tais como terceirização de atividades, contratação de seguro ou hedge;

- evitar - paralisar a atividade geradora de risco, podendo significar a descontinuidade 
de algumas ou de toda a operação; e

- reduzir - são estabelecidas medidas e procedimentos para mitigar a probabilidade e/ ou o impacto do risco.

As atividades de controle são as políticas e procedimentos implementados com o intuito de assegurar a efetividade e eficiência de uma política de gestão de riscos (COSO, 2004a, p. 62), podendo ser consideradas também como uma resposta aos riscos (COSO, 2004a, p. 68).

\subsection{Atividades de monitoramento}

Neste trabalho, serão utilizados os conceitos do COSO (2004b), em relação ao monitoramento. As atividades de monitoramento possuem o intuito de avaliar a eficiểncia e eficácia dos componentes do gerenciamento de riscos, podendo ser realizadas da seguinte forma (COSO, 2004b, p. 85):

- Monitoramento contínuo - os mecanismos e procedimentos para o gerenciamento de riscos são estruturados para a realização desta tarefa de forma contínua, no transcorrer das operações de uma organização, constituindo uma importante fonte de feedback das atividades de controle, além de responderem de forma mais tempestiva em relação à avaliação independente;

- Independente - avalia-se o gerenciamento dos riscos como um todo, podendo o seu escopo abranger a totalidade das operações da empresa ou parte dela, com o intuito de verificar a sua funcionalidade. Portanto, avaliam-se novamente os riscos, a experiência do pessoal, as respostas aos riscos, as atividades de controle vigentes e o monitoramento contínuo;

- Combinação de ambas as técnicas.

O foco e a frequência das avaliações dependem do nível de risco envolvido. Para identificar as atividades de monitoramento da Empresa A, serão entrevistados o consultor tributário externo e o contabilista.

\section{RESULTADOS DO ESTUDO DE CASO}

4.1 Processos realizados pela empresa para o cumprimento das obrigações acessórias tributárias paulistas.

No ano de 2003, a Empresa A foi objeto de auditoria fiscal que resultou na lavratura de uma multa cujo montante impactou de forma significativa o resultado da empresa naquele exercício (o resultado em 2003 foi de aproximadamente $\mathrm{R} \$ 2.000 .000,00$ ).

As irregularidades constatadas não foram apenas de caráter tributário, mas também de inconsistências contábeis, com repercussão no âmbito tributário. Nesta época, os sistemas não eram integrados e não havia nenhum procedimento de controle interno ou de gerenciamento de riscos. Para diminuir o risco de uma nova autuação fiscal, os diretores contrataram dois consultores tributários externos para uma revisão completa dos processos e procedimentos internos da empresa, com vistas à redução dos riscos de desconformidade tributária.

\subsubsection{Notas fiscais}

\subsubsection{Procedimentos relacionados às notas fiscais de entrada até 2003}


O setor do almoxarifado, ao receber os insumos, conferia a quantidade entregue com o descrito na nota fiscal, inserindo a quantidade no sistema de estoque; ato contínuo, o setor enviava a nota fiscal para o departamento de compras para o confronto com o pedido. Estando em conformidade, a nota fiscal era enviada ao departamento financeiro para o cadastro no sistema de pagamentos, e era finalmente enviada ao departamento de contabilidade, que a cadastrava no sistema contábil/fiscal e processava o seu arquivamento.

Segundo o consultor tributário, devido à falta de integração entre os sistemas, havia uma redundância de procedimentos, sendo a nota fiscal inserida diversas vezes em sistemas diferentes, muito embora não sejam sempre as mesmas informações. Outro problema recorrente era que a nota fiscal era confrontada apenas quando tramitava pelo departamento de compras, ou seja, após o recebimento dos insumos. Isso causava transtornos quando havia a necessidade de devolução do pedido.

Não havia durante todo este processo a realização de conferência sobre os dados inseridos no sistema. A falta deste procedimento, aliado ao fato dos sistemas não serem integrados, expunha a empresa a diversos riscos.

Segundo o consultor tributário, era comum ocorrerem problemas no inventário, duplicatas não cadastradas no sistema e irregularidades na contabilidade, o que ocasionou a imposição de penalidades por parte do Fisco, principalmente quanto à falta de escrituração de notas fiscais, de valores escriturados em valores superiores ao real e aquisição de mercadorias por empresas consideradas inidôneas ou inativas pelo Fisco.

\subsubsection{Procedimentos realizados com as notas fiscais de saída até 2003}

Após a emissão da nota fiscal, esta era enviada ao departamento financeiro para o cadastro das duplicatas, ao departamento de contabilidade para que este cadastrasse o documento fiscal em seu sistema contábil/fiscal, e remetida à expedição para o despacho das mercadorias ao cliente.

Os procedimentos acima não contemplavam a conferência das informações contidas nas notas fiscais de saídas com os diversos sistemas existentes, além de não ser realizada a consulta em relação à situação cadastral do cliente no site do Sistema Integrado de Informações sobre Operações Interestaduais com Mercadorias e Serviços (SINTEGRA).

Diariamente, o departamento financeiro emitia um relatório contendo as duplicatas quitadas pelos clientes e que era encaminhado à contabilidade para que este promovesse o registro contábil de liquidação, o que nem sempre era realizado.

Segundo o consultor, ocorriam problemas principalmente com o departamento de contabilidade, tais como notas fiscais não registradas ou registradas erroneamente, a emissão de notas fiscais para clientes em situação irregular perante o fisco e a falta de lançamento, na contabilidade, das duplicatas de clientes já quitadas, o que ocasionou a imposição de penalidades por parte do fisco, sendo que o maior montante teve como origem a falta de contabilização da baixa das duplicatas, pois esta falta ocasionava saldo insuficiente nas disponibilidades e que eram saneadas através de empréstimos fictícios. 


\subsubsection{Procedimentos revisados e modificados a partir de 2003}

Cabe ao departamento de contabilidade realizar a classificação fiscal deste produto, inserindo a redução da base de cálculo e as alíquotas de ICMS aplicáveis, conforme o tipo de operação, sendo este procedimento realizado pelo contabilista. Da mesma forma, incumbe a este departamento o cadastro de novos clientes e as análises sob o ponto de vista tributário, tais como consulta ao site do SINTEGRA e qual unidade da federação em que se encontra. Anteriormente, o cadastro era de responsabilidade do departamento de vendas.

A revisão realizada e a implantação de modificações nos processos e procedimentos perduram até a época da realização do presente estudo de caso, conforme será explanado a seguir. Segue relação de processos e procedimentos implantados pela Empresa A após 2003:

\begin{tabular}{|c|c|c|}
\hline Processos e procedimentos & pré 2003 & pós 2003 \\
\hline Sistema de informações integrado & não & $\operatorname{sim}$ \\
\hline Equipamentos de armazenamento em duplicidade & não & $\operatorname{sim}$ \\
\hline Consulta da situação cadastral fiscal do fornecedor & não & sim \\
\hline Consulta da situação cadastral fiscal do cliente & não & $\operatorname{sim}$ \\
\hline Cadastro de nota fiscal apenas uma vez & não & $\operatorname{sim}$ \\
\hline Conferência dos dados da nota fiscal inseridos no sistema & não & $\operatorname{sim}$ \\
\hline Conferência dos lançamentos contábeis e fiscais & não & $\operatorname{sim}$ \\
\hline Conferência física das notas fiscais & não & $\operatorname{sim}$ \\
\hline Análise prévia da situação tributária dos produtos pelo departamento de & não & \multirow{2}{*}{$\operatorname{sim}$} \\
\hline
\end{tabular}

Quadro 4: Relação de processos e procedimentos implantados pela Empresa A após 2003

Fonte: Elaborado pelo autor

Ressalta o consultor tributário que a implantação dos novos procedimentos foi precedida de treinamento intenso para os funcionários que o operacionalizam, ministrados pelos consultores contratados, procurando também conscientizá-los da importância de realizálos de forma correta.

\subsubsection{Procedimentos em relação às notas fiscais de entrada - após 2003}

Ao recepcionar as mercadorias, a primeira providência do almoxarifado é consultar a situação cadastral perante o fisco (se nota fiscal modelo 1/1A) ou a autenticidade da nota fiscal eletrônica.

O entrevistado afirma que este procedimento é de suma importância, visto que a legislação tributária paulista não permite a apropriação de ICMS destacado no Documento Auxiliar da Nota Fiscal Eletrônica (DANFE), mas apenas da Nota Fiscal Eletrônica (NFE) regularmente emitida e de contribuinte em situação regular, o que reduz o risco de receber mercadorias por empresas consideradas inidôneas pelo fisco. O setor do almoxarifado também é o responsável pelo confronto da nota fiscal com o pedido, assim como a sua baixa perante o sistema.

Após a recepção das mercadorias e realização dos procedimentos de alçada, a nota fiscal (ou DANFE) é remetida ao departamento de compras, depois ao departamento financeiro, e finalmente a nota fiscal é enviada ao departamento de contabilidade para proceder ao que 
segue:

- tratando-se de nota fiscal eletrônica, localizar e armazenar o arquivo em extensão $\mathrm{XML}^{4}$ enviado (ou que deveria ter sido), pelo emitente, ao e-mail da empresa;

- conferir todas as informações contidas na nota fiscal (ou DANFE), por amostragem, que foram inseridas pelo setor do almoxarifado (ou de aquisições diversas), confirmando a sua inclusão nos sistemas contábil e fiscal;

- custódia das notas fiscais.

O consultor tributário afirma que a implantação destes novos procedimentos reduziu sensivelmente: as inconsistências no inventário, os erros na escrituração contábil e fiscal, a aquisição de mercadorias por empresas inidôneas ou inativas, problemas ocasionados com fornecedores que não aceitavam a nota fiscal de devolução e eliminou a ocorrência de duplicatas de fornecedores não cadastrados.

\subsubsection{Procedimentos com as notas fiscais de saída, de 2003 a 2009}

Segundo o consultor, a Empresa A emitiu notas fiscais de saída até o final de 2009, e, no início de 2010, iniciou a emissão de notas fiscais eletrônicas. Constatou-se através de observações que a emissão de notas fiscais de saída é realizada pelo setor de faturamento, subordinado ao departamento financeiro.

Segundo o entrevistado, com a integração dos sistemas, foram eliminadas as várias inserções dos dados da nota fiscal pelos departamentos em que ela tramitava até a chegada à expedição. Com a integração dos sistemas, foram implantados rotinas de verificação, por amostragem, das notas fiscais emitidas juntamente com as informações contidas no sistema contábil/fiscal. Assim, foram reduzidas: as ocorrências de notas fiscais não registradas ou preenchidas irregularmente, as inconsistências no estoque de produtos acabados e extravio de notas fiscais.

O consultor afirma que a Empresa A já foi penalizada quando emitia nota fiscal cujo erro de preenchimento resultava em cálculo de ICMS menor do que o devido, sendo relevados os demais erros de preenchimento tais como endereço, número de inscrição no Cadastro Nacional de Pessoa Jurídica (CNPJ) e número de inscrição estadual. Segue quadro abaixo contendo, de forma resumida, as ações implementadas após 2003 e os eventos adversos evitados.

4 XML- Extensible Markup Language - É um formato para a criação de documentos digitais, cuja principal característica deste tipo de arquivo é a possibilidade de leitura por programas escritos para diversos sistemas (RICCIO; SAKATA; MOREIRA; QUONIAN, 2006). 


\begin{tabular}{|c|c|}
\hline Ações implementadas após 2003 & Eventos adversos evitados \\
\hline $\begin{array}{l}\text { - aquisição de equipamento para armazenamento } \\
\text { de dados em duplicidade; } \\
\text { - } \quad \text { manisição de sistema de informações integrado; } \\
\text { - } \quad \text { internet; } \\
\text { consulta da situação cadastral fiscal do } \\
\text { fornecedor e do cliente; } \\
\text { cadastro de uma única vez da nota fiscal de } \\
\text { entradas; } \\
\text { conferência pelo departamento de } \\
\text { contabilidade dos lançamentos levados a } \\
\text { efeito; } \\
\text { classificação tributária dos produtos e insumos } \\
\text { a cargo do depto. de contabilidade. }\end{array}$ & 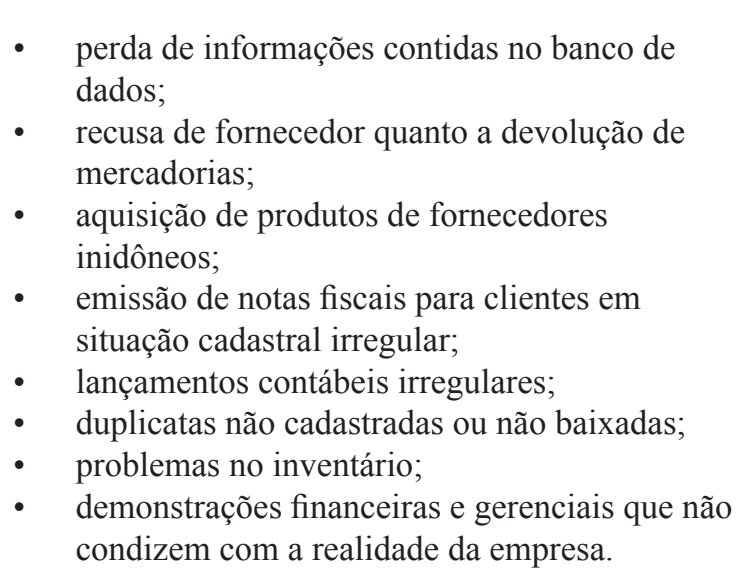 \\
\hline
\end{tabular}

Quadro 5: Ações implementadas após 2003 e os eventos adversos evitados

Fonte: Dados da pesquisa

Os benefícios gerenciais advindos de melhores procedimentos visando a conformidade tributária já foram previstos por Sandford, Godwin e Hardwick (1989), Tran-Nam et al. (2000), Pope (1993) e Evans (2001).

\subsubsection{Procedimentos para a emissão da nota fiscal eletrônica - a partir de 2009}

Muito embora a emissão das notas fiscais eletrônicas tenha-se iniciado em 2010, a Empresa A iniciou os preparativos e testes ainda no exercício de 2009.

Segundo o entrevistado, houve um treinamento para o pessoal da contabilidade e para o faturista, ministrado pela empresa responsável pelo desenvolvimento do sistema, seguido de um período de testes. Durante esta fase, aproximadamente $40 \%$ dos arquivos digitais submetidos à validação pela Secretaria da Fazenda do Estado de São Paulo (SEFAZ/SP) retornavam inconsistentes devido a problemas no cadastro dos clientes, não autorizando a emissão. Alguns dos erros encontrados foram: clientes que se encontravam inativos, endereço desatualizado, erros no preenchimento de CNPJ, da inscrição estadual e do nome empresarial.

Ocorreram problemas também de conexão com os servidores da SEFAZ/SP, bem como a geração de arquivos digitais fora do padrão estabelecido. Para o saneamento de sua base de dados, os funcionários do departamento de contabilidade foram convocados durante dois finais de semana consecutivos para a depuração dos erros, através de consulta ao site do SINTEGRA.

O entrevistado afirmou que antes da implantação da nota fiscal eletrônica, não havia uma preocupação por parte da empresa em manter atualizado o cadastro de clientes, e consequentemente não era rara a emissão de notas fiscais contendo informações incorretas. As ocorrências mais corriqueiras eram problemas no CNPJ e/ou inscrição estadual cancelada, bloqueada ou suspensa; endereço ou razão social incorretos; emissão de nota fiscal a uma filial desativada de um cliente.

A implantação da nota fiscal eletrônica eliminou a possibilidade destas ocorrências, salvo quando o cancelamento ou alteração cadastral ocorre de forma retroativa. Houve também um benefício de ordem gerencial, pois a realização de venda para empresas que não estivessem ativas, dificultava o recebimento das duplicatas mercantis. 


\subsection{Identificação e avaliação dos riscos à conformidade tributária}

Esta etapa é imprescindível para que a empresa possa identificar os riscos relevantes e determinar uma resposta apropriada. Os dados referentes às ocorrências e à frequência são resultados de relatórios elaborados por iniciativa do consultor tributário externo, com o auxílio do contabilista. Quanto à avaliação dos riscos, os entrevistados informaram que utilizaram as experiências sofridas com auditorias realizadas pelo fisco nos últimos doze anos.

\subsubsection{Identificação de riscos e de sua ocorrência}

Os riscos identificados a seguir não ocorrem, necessariamente, em cada um destes setores ou departamentos, mas são considerados pela empresa como responsáveis pela sua ocorrência, sendo os dados das ocorrências relativos aos anos de 2003 e 2010.

.a-) Setor do almoxarifado:

Tabela 1: Identificação de riscos atribuídos ao setor do almoxarifado

\begin{tabular}{|l|c|c|}
\hline \multirow{2}{*}{ EVENTOS } & \multicolumn{2}{c|}{ OCORRÊNCIA/TOTAL } \\
\cline { 2 - 3 } & 2003 & 2010 \\
\hline a1 - Falta de consulta da NF no site SINTEGRA & não consult. & $600 / 15.248$ \\
\hline a2 - Falta de consulta da NFE na SEFAZ do emitente & não consult. & $600 / 12.127$ \\
\hline a3 - Aceitação de mercadorias com preço diferente ao do pedido & $440 / 9.172$ & $180 / 15.248$ \\
\hline a4 - Inserção no sistema de quantidade diferente ao da NF/NFE & $4.300 / 9.172$ & $1.320 / 15.248$ \\
\hline
\end{tabular}

Fonte: Elaborada pelo autor com dados da pesquisa

b-) Departamento financeiro:

Tabela 2: Identificação de risco atribuído ao departamento financeiro

\begin{tabular}{|c|c|c|}
\hline \multirow{2}{*}{ EVENTOS } & \multicolumn{2}{|c|}{ OCORRÊNCIA/TOTAL } \\
\cline { 2 - 3 } & 2003 & 2010 \\
\hline b1 - Falta de registro de pagamento/recebimento & $20.160 / 63.339$ & $1.680 / 139.963$ \\
\hline
\end{tabular}

Fonte: Elaborado pelo autor com dados da pesquisa

c-) Departamento de contabilidade: 
Tabela 3: Identificação de riscos atribuídos ao departamento de contabilidade

\begin{tabular}{|l|c|c|}
\hline \multicolumn{1}{|c|}{ EVENTOS } & \multicolumn{2}{c|}{ OCORRÊNCIA/TOTAL } \\
\cline { 2 - 3 } & 2003 & 2010 \\
\hline c1 - Erro na escrituração fiscal do crédito de ICMS & $180 / 9.172$ & $24 / 15.248$ \\
\hline c2 - Extravio de NF/NFE de entrada & $36 / 790$ & $6 / 1338$ \\
\hline c3 - Escrituração de NF considerada inidônea pelo Fisco & $25 / 217$ & $7 / 367$ \\
\hline c4 - Erro na escrituração contábil & $27.296 / 72.791$ & $2.400 / 157.20$ \\
\hline c5 - Erro na determinação de ICMS na saída dos produtos & $240 / 20.301$ & $120 / 33.650$ \\
\hline c6 - Emissão de NF/NFE para contribuinte em situação irregular & $480 / 20.301$ & $72 / 33.650$ \\
\hline c7 - Emissão de NF/NFE com irregularidade no preenchimento & $3.197 / 20.301$ & $960 / 33.650$ \\
\hline c8 - Falta de escrituração de NF de entrada & $180 / 9.172$ & $30 / 15.248$ \\
\hline c9 - Erro no cálculo e apropriação de crédito acumulado de ICMS & não realizava & $5 / 12$ \\
\hline c10 - Geração de arquivos digitais SINTEGRA inconsistentes & $12 / 12$ & $12 / 2$ \\
\hline c11 - Geração de livros fiscais inconsistentes & $24 / 36$ & $6 / 36$ \\
\hline c12 - Declaraçães tributárias inconsistentes/intempestivas & $8 / 12$ & $6 / 12$ \\
\hline
\end{tabular}

Fonte: Elaborada pelo autor com dados da pesquisa

Segundo o consultor tributário externo, as ocorrências do risco c3 são por fornecedor; já o risco c2, normalmente ocorre com notas fiscais com valores acima de R\$ 5.000,00 (cinco mil reais), pois estas notas fiscais são solicitadas por outros departamentos, tais como o de compras e financeiro, para a checagem de eventuais inconsistências comerciais. Desta forma, a verificação ocorre com notas fiscais que possuem valor igual ou superior a este limite.

d-) Sistema de informações e equipamentos:

Tabela 4: Identificação de riscos atribuídos a sistemas de informações e equipamentos

\begin{tabular}{|l|c|c|}
\hline \multicolumn{1}{|c|}{ EVENTOS } & \multicolumn{2}{|c|}{ OCORRÊNCIA/TOTAL } \\
\cline { 2 - 3 } & 2003 & 2010 \\
\hline $\begin{array}{l}\text { d1 - Problemas nos sistemas de informações (pane/erros de programação/vírus de } \\
\text { computador) }\end{array}$ & 1.164 & 480 \\
\hline d2 - Problemas nos equipamentos de armazenamento & 6 & 2 \\
\hline d3 - Acesso à internet para o envio de declarações fiscais & 48 & 24 \\
\hline
\end{tabular}

Fonte: Elaborada pelo autor com dados da pesquisa 


\subsubsection{Classificação dos eventos por fatores de risco}

Utilizando-se dos riscos identificados nas Tabelas 1 a 4, e relacionando-os aos fatores de risco, tem-se o seguinte panorama:

\begin{tabular}{|c|c|c|c|c|c|c|c|c|}
\hline & \multirow[b]{2}{*}{ Riscos identificados } & \multicolumn{3}{|c|}{ fatores internos } & \multicolumn{4}{|c|}{ fatores externos } \\
\hline & & 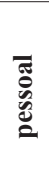 & 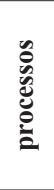 & 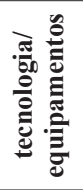 & 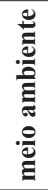 & 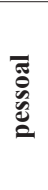 & 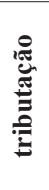 & 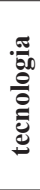 \\
\hline & ALMOXARIFADO & & & & & & & \\
\hline a1 & Falta de consulta da NF no site SINTEGRA & $X$ & & & & & & \\
\hline $\mathrm{a} 2$ & Falta de consulta da NFE na SEFAZ do emitente & $\mathrm{X}$ & & & & & & \\
\hline a3 & Aceitação de mercadorias com preço diferente ao do pedido & $\mathrm{X}$ & & & & & & \\
\hline \multirow[t]{2}{*}{ a4 } & Inserção no sistema de quantidade diferente ao da NF/NFE & $\mathrm{X}$ & & & & & & \\
\hline & DEPARTAMENTO FINANCEIRO & & & & & & & \\
\hline \multirow[t]{2}{*}{ b1 } & Falta de registro de pagamento & $\mathrm{X}$ & & & & & & \\
\hline & DEPARTAMENTO DE CONTABILIDADE & & & & & & & \\
\hline $\mathrm{c} 1$ & Erro na escrituração fiscal do crédito de ICMS & $\mathrm{X}$ & $\mathrm{X}$ & & & & $\mathrm{X}$ & \\
\hline $\mathrm{c} 2$ & Extravio de NF/NFE de entrada & $\mathrm{X}$ & & & & & & \\
\hline c3 & Escrituração de NF considerada inidônea pelo Fisco & $\mathrm{X}$ & & & & $\mathrm{X}$ & $\mathrm{X}$ & \\
\hline $\mathrm{c} 4$ & Erro na escrituração contábil & $\mathrm{X}$ & $\mathrm{X}$ & & & & & \\
\hline c5 & Erro na determinação de ICMS na saída dos produtos & $\mathrm{X}$ & & & & & $\mathrm{X}$ & \\
\hline c6 & Emissão de NF/NFE para contribuinte em situação irregular & $\mathrm{X}$ & $\mathrm{X}$ & & & & $\mathrm{X}$ & \\
\hline $\mathrm{c} 7$ & Emissão de NF/NFE com irregularidade no preenchimento & $\mathrm{X}$ & & & & & $\mathrm{X}$ & \\
\hline $\mathrm{c} 8$ & Falta de escrituração de NF de entrada & $\mathrm{X}$ & & & & & & \\
\hline c9 & Erro no cálculo e apropriação de crédito acumulado de ICMS & $\mathrm{X}$ & & & & & $\mathrm{X}$ & \\
\hline $\mathrm{c} 10$ & Geração de arquivos digitais SINTEGRA inconsistentes & $\mathrm{X}$ & $\mathrm{X}$ & $\mathrm{X}$ & & & $\mathrm{X}$ & \\
\hline c11 & Geração de livros fiscais inconsistentes & $\mathrm{X}$ & $\mathrm{X}$ & $\mathrm{X}$ & & & $\mathrm{X}$ & $\mathrm{X}$ \\
\hline \multirow[t]{2}{*}{$\mathrm{c} 12$} & Declarações tributárias inconsistentes/intempestivas & $\mathrm{X}$ & $\mathrm{X}$ & $\mathrm{X}$ & & & $\mathrm{X}$ & $\mathrm{X}$ \\
\hline & SISTEMAS DE INFORMAÇÕES E EQUIPAMENTOS & & & & & & & \\
\hline $\mathrm{d} 1$ & $\begin{array}{l}\text { Problemas nos sistemas de informações (pane/erros de } \\
\text { programação/vírus de computador) }\end{array}$ & $\mathrm{X}$ & & $\mathrm{X}$ & & $\mathrm{X}$ & & $\mathrm{X}$ \\
\hline $\mathrm{d} 2$ & Problemas nos equipamentos de armazenamento & & & $\mathrm{X}$ & & & & $\mathrm{X}$ \\
\hline $\mathrm{d} 3$ & Acesso à internet para o envio de declarações fiscais & & & $\mathrm{X}$ & $\mathrm{X}$ & & & $\mathrm{X}$ \\
\hline
\end{tabular}

Quadro 6: Relação entre os riscos e os fatores de risco

Fonte: Elaborado pelo autor com dados da pesquisa

O consultor tributário afirma que os fatores de risco são independentes entre si, não sendo necessária a ocorrência simultânea de dois ou mais fatores para influenciar o risco a ele relacionado.

\subsubsection{Avaliação dos riscos à conformidade tributária paulista}

Com a utilização da graduação contida nos Quadros 2 e 3, e após a classificação da probabilidade e do impacto dos riscos por parte da Empresa A, tem-se a seguinte tabela: 
Tabela 5: Classificação dos riscos segundo a sua probabilidade e impacto na Empresa A

\begin{tabular}{|c|c|c|c|}
\hline & Riscos identificados & probabilidade & impacto \\
\hline & ALMOXARIFADO & & \\
\hline a1 & Falta de consulta da NF no site SINTEGRA & 5 & 4 \\
\hline a2 & Falta de consulta da NFE na SEFAZ do emitente & 5 & 4 \\
\hline a3 & Aceitação de mercadorias com preço diferente ao do pedido & 1 & 1 \\
\hline \multirow[t]{2}{*}{ a4 } & Inserção no sistema de quantidade diferente ao da NF/NFE & 3 & 3 \\
\hline & DEPARTAMENTO FINANCEIRO & & \\
\hline \multirow[t]{2}{*}{ b1 } & Falta de registro de pagamento & 4 & 4 \\
\hline & DEPARTAMENTO DE CONTABILIDADE & & \\
\hline $\mathrm{c} 1$ & Erro na escrituração fiscal do crédito de ICMS & 5 & 2 \\
\hline $\mathrm{c} 2$ & Extravio de NF/NFE de entrada & 4 & 2 \\
\hline c3 & Escrituração de NF considerada inidônea pelo Fisco & 5 & 4 \\
\hline c5 & Erro na determinação de ICMS na saída dos produtos & 4 & 5 \\
\hline c6 & Emissão de NF/NFE para contribuinte em situação irregular & 1 & 3 \\
\hline c7 & Emissão de NF/NFE com irregularidade no preenchimento & 1 & 1 \\
\hline c8 & Falta de escrituração de NF de entrada & 1 & 2 \\
\hline c9 & Erro no cálculo e apropriação de crédito acumulado de ICMS & 5 & 3 \\
\hline $\mathrm{c} 10$ & Geração de arquivos digitais SINTEGRA inconsistentes & 1 & 4 \\
\hline $\mathrm{c} 11$ & Geração de livros fiscais inconsistentes & 1 & 3 \\
\hline $\mathrm{c} 12$ & Declarações tributárias inconsistentes/intempestivas & 1 & 3 \\
\hline & SISTEMAS DE INFORMAÇÕES E EQUIPAMENTOS & & \\
\hline d1 & $\begin{array}{l}\text { Problemas nos sistemas de informações (pane/erros de programação/ } \\
\text { vírus de computador) }\end{array}$ & 2 & 2 \\
\hline $\mathrm{d} 2$ & Problemas nos equipamentos de armazenamento & 1 & 4 \\
\hline $\mathrm{d} 3$ & Acesso à internet para o envio de declarações fiscais & 1 & 1 \\
\hline
\end{tabular}

Fonte: Elaborado pelo autor com dados

O entrevistado esclarece que os riscos a1 e a2 podem ocasionar o c3; os a3, a4 e b1, ocasionam o c4.

\subsubsection{Respostas aos riscos à conformidade tributária e as atividades de controle}

Segundo o consultor tributário, devido às peculiaridades dos riscos à conformidade tributária, não há como a Empresa A compartilhar ou evitar o risco. Mesmo que contrate uma apólice de seguro que ofereça tal cobertura, a responsabilidade pelo pagamento é da Empresa A; quanto a evitar o risco, representaria simplesmente o encerramento das atividades da empresa.

O entrevistado afirma que a posição da Empresa A é a de redução de todos os riscos tributários, pois a aceitação implicaria em redução do resultado e até a diminuição de seu patrimônio.

Segundo o consultor tributário, as atividades de controle implantadas para o gerenciamento do risco tributário são as abaixo relacionadas, além daquelas discriminadas no Quadro 4:

- Integração dos sistemas (após 2003);

- Tratando-se de Nota Fiscal Eletrônica, localização do arquivo digital enviado pelo emitente (após 2006);

- Conferência física das notas fiscais (após 2003).

Além dos acima relacionados, a Empresa A custeia cursos de atualização tributária 
e contábil, frequentados pelo contabilista e pelo consultor tributário externo, permitindo que fiquem atualizados com a legislação tributária vigente.

Conforme relato dos entrevistados, os riscos identificados como c6, c7, c8, c10, c11, c12 e d3, são relevados pela Empresa A, quer seja pela baixa probabilidade, quer seja pelo reduzido impacto nos resultados, não sendo dispensada muita atenção. Entretanto, isso não significa que são totalmente ignorados, mas apenas que não são prioritários.

O consultor tributário ressalta que em função da obrigatoriedade da escrituração digital, tanto a contábil como a fiscal, serem realizadas em ambiente do Sistema Público de Escrituração Digital (SPED), por sua sugestão a Empresa A contratou um profissional para a criação de um novo sistema de informações visando a eliminação total de inconsistências em seus lançamentos e $100 \%$ de conformidade à legislação tributária aplicável.

\subsubsection{Monitoramento}

As atividades identificadas são as seguintes:

- Cursos de atualização tributária;

- Assinatura de serviço de atualização tributária;

- Tabulação dos resultados de conciliação de contas e da conferência dos lançamentos, comparando-os em relação a períodos anteriores.

Os entrevistados informaram também serem os responsáveis por avaliar tanto os sistemas de informação como os equipamentos utilizados para a realização dos procedimentos relacionados à tributação. O consultor tributário destaca que sempre ao detectar a necessidade de modificar os procedimentos e processos relacionados à tributação, os diretores solicitam a apresentação dos motivos das alterações, mas que nunca vetaram as sugestões de melhoria do gerenciamento de riscos tributários. O treinamento aos funcionários é sempre ministrado pelo consultor tributário, com exceção da implantação de novas rotinas ou modificações no sistema de informações, que são de responsabilidade da empresa que as desenvolve, mas sempre sob a supervisão do consultor tributário.

\subsection{Identificação dos fatores de risco}

\subsubsection{Apresentação das atividades de controle e de resposta aos riscos, por fatores de risco}

Nesta subseção, serão analisadas as atividades de controle e resposta a riscos estabelecidas pela Empresa A, com o intuito de se reduzirem os riscos tributários, o que poderá provocar, porém, uma elevação nos custos de conformidade tributária. Para o presente estudo de caso, infere-se que os fatores de risco são independentes, sendo que os de maior incidência são aqueles classificados como pertencentes ao ambiente interno.

\subsubsection{Fator de risco: pessoal - ambiente interno}

A implementação de uma política de conscientização tem, como intuito, transmitir a todos os funcionários que tenham relação com os processos e procedimentos voltados à tributação, sobre a importância de sua realização de forma correta, pois o aumento dos riscos 
tributários expõe a empresa a multas fiscais, cujos reflexos negativos podem afetar a todos, inclusive pondo em risco a continuidade da empresa. Essa resposta está presente em sete dos riscos tributários identificados, seguida dos gastos com cursos de atualização tributária, que são citadas cinco vezes. Este fator de risco é o de maior incidência, corroborando com a pesquisa realizada pela Ernst \& Young (2008), na qual os recursos humanos foram considerados um fator importantíssimo de risco tributário.

\subsubsection{Fator de risco: processos - ambiente interno}

Este fator de risco envolveu não apenas a aquisição de um sistema de informações integrado, mas também a implementação de diversos processos e procedimentos, relacionados à tributação, até então inexistentes na empresa. Se por um lado aumentou a burocracia interna, por outro reduziu os riscos tributários, contribuindo também para uma maior consistência do sistema de informações. O sistema de informações integrado permitiu ao consultor tributário realizar outras atividades de controle e resposta aos riscos, como as verificações e as conciliações entre os registros contábeis e fiscais, melhorando a eficiência do gerenciamento dos riscos tributários.

A revisão dos processos e procedimentos relacionados à tributação proporcionou maior consistência e confiabilidade das informações contidas em seu banco de dados e permitiu a sua utilização de forma gerencial.

\subsubsection{Fator de risco: tecnologia/equipamentos - ambiente interno}

A aquisição de equipamento para armazenamento de dados em duplicidade é uma resposta ao risco presente em três ocorrências, assim como a manutenção e avaliação periódica sobre a necessidade de troca de equipamentos. A manutenção e avaliação periódica sobre a necessidade de troca de equipamentos contribuem para uma maior eficiência dos processos e procedimentos, pois panes e equipamentos lentos podem ser grandes obstáculos que levam a um aumento do tempo a ser dispensado para a satisfação das obrigações tributárias acessórias pelos funcionários.

\subsubsection{Fator de risco: meio ambiente - fator externo}

Representada por ações da natureza, podem ocasionar diversos problemas tais como a queda e interrupção de energia, ou avarias por descarga elétrica. A resposta a este fator foi a instalação de no-break e a manutenção periódica dos para-raios já instalados, procurando desta forma evitar a paralisação abrupta do sistema, o que pode acarretar perda de informações, e possíveis danos nos equipamentos em função de uma descarga elétrica.

\subsubsection{Fator de risco: pessoal - fator externo}

Este fator aparece em apenas dois riscos: c3 e d1. São casos de pessoas estranhas à empresa e que podem contribuir para o aumento do risco tributário. As respostas selecionadas face a este fator foram as seguintes:

- em relação ao risco c3, exigência de pagamento em conta-corrente do fornecedor, ou a emissão por parte deste de boleto bancário; 
- em relação ao risco d1, a instalação de firewall e antivírus.

\subsubsection{Fator de risco: tributação - fator externo}

Este fator está sempre presente quando os riscos são diretamente ligados a questões tributárias. A resposta selecionada pela Empresa A foi a realização de cursos de atualização tributária e a assinatura de serviço de atualização tributária, face à complexidade da legislação tributária paulista e a federal. O consultor externo tem a liberdade de escolher os cursos e contratá-los, sob às expensas da empresa, sempre que julgar necessário.

\subsubsection{Fator de risco: tecnologia - ambiente externo}

As respostas a este fator foram a contratação de dois provedores de acesso à internet, e a realização de avaliações periódicas sobre a necessidade de troca de equipamentos.

\subsubsection{Análise qualitativa dos riscos tributários}

Conforme discorrido no sub item 4.2.4, há certos riscos tributários considerados prioritários pela Empresa A. Segue Tabela 6 contendo a classificação em função da resposta aos riscos.

Tabela 6: Análise qualitativa dos riscos tributários identificados

\begin{tabular}{|c|c|c|c|}
\hline risco & resposta ao risco & probabilidade & impacto \\
\hline c1 & redução do risco & 5 & 2 \\
\hline c2 & redução do risco & 4 & 2 \\
\hline c3 & redução do risco & 5 & 4 \\
\hline c4 & redução do risco & 3 & 4 \\
\hline c5 & redução do risco & 4 & 3 \\
\hline c6 & aceitar o resultado & 1 & 3 \\
\hline c7 & aceitar o resultado & 1 & 1 \\
\hline c8 & aceitar o resultado & 1 & 2 \\
\hline c9 & redução do risco & 5 & 3 \\
\hline c10 & aceitar o resultado & 1 & 4 \\
\hline c11 & aceitar o resultado & 1 & 3 \\
\hline c12 & aceitar o resultado & 1 & 3 \\
\hline d1 & redução do risco & 2 & 2 \\
\hline d2 & redução do risco & 1 & 4 \\
\hline d3 & aceitar o resultado & 1 & 1 \\
\hline
\end{tabular}

Fonte: Elaborada pelo autor com dados da pesquisa

Muito embora a probabilidade seja tão somente um dos componentes para a avaliação e determinação do risco (PENHA; PARISI, 2005), analisando a tabela acima, com exceção dos riscos $\mathrm{d} 1$ e d2, percebe-se que a classificação da resposta ao risco (em redução do risco ou aceitar o resultado), ocorre em função da probabilidade de o risco transformar-se em multa tributária, e não em função do impacto no resultado. Essa afirmativa é corroborada com a mudança da classificação do risco c10, que em 2011 teve a sua probabilidade elevada para 5, levando a empresa a concentrar esforços para o saneamento os arquivos digitais SINTEGRA, em função da obrigatoriedade em realizar a escrituração contábil e fiscal de forma digital e enviá-los ao SPED, sendo que esta preocupação em relação à exatidão dos dados enviados ao SPED também foi constatada por Oliveira (2009). 
Apesar do impacto no resultado ser a própria expressão do grau de risco, a empresa considerou a probabilidade da materialização do risco em multa tributária como fator preponderante para a determinação das respostas aos riscos.

Dos modelos desenvolvidos e utilizados neste estudo, a avaliação qualitativa vem preencher um espaço deixado pela avaliação quantitativa, pois esta não leva em consideração a probabilidade de que, em ocorrendo o risco, a sua materialização em multa tributária irá ocorrer somente se a empresa passar por uma fiscalização, e esta auditoria detectar a irregularidade. As observações colhidas no estudo de caso apontam para o seguinte levantamento preliminar, de pontos fortes e fracos do método qualitativo:

\section{Pontos fortes}

- permite a classificação de todos os riscos;

- possibilita considerar a percepção do entrevistado em relação à provável materialização do risco tributário em multa, o que apenas ocorrerá se a empresa passar por uma auditoria por parte do Fisco, e este detectar a irregularidade;

- proporciona ao pesquisador captar a realidade social através de suas observações;

- prescinde de auditoria interna/externa para a mensuração de todos os riscos tributários;

- torna possível compreender a relação entre os fatores de risco, o risco e as respostas selecionadas para a sua redução.

Pontos fracos:

- alto grau de subjetividade na classificação da probabilidade de o risco materializarse em multa tributária e em impacto no resultado;

- não possibilita a mensuração econômica dos riscos tributários.

\subsubsection{Análise quantitativa dos riscos}

Segue a Tabela 7 contendo os cálculos dos riscos tributários, dos anos de 2003 e 2010.

Tabela 7: Comparação dos riscos tributários dos exercícios de 2003 e 2010

\begin{tabular}{|c|c|c|c|c|c|}
\hline & $\begin{array}{c}2003 \\
\text { média X } \\
\text { ocorrências }\end{array}$ & $\begin{array}{c}2010 \\
\text { média } x \\
\text { ocorrências }\end{array}$ & $\begin{array}{c}2003 \\
\text { faturamento } \\
\text { fato }\end{array}$ & $\begin{array}{c}2010 \\
\text { fodo } \\
\text { faturamento }\end{array}$ & $\begin{array}{c}\text { redução do } \\
\text { risco }\end{array}$ \\
\hline c1 & $20.190,51$ & $36.599,00$ & $0,06118 \%$ & $0,0421 \%$ & $31,24 \%$ \\
\hline c2 & $174.235,32$ & $32.945,28$ & $0,52799 \%$ & $0,0379 \%$ & $92,83 \%$ \\
\hline c3 & $664.582,93$ & $351.941,59$ & $2,01389 \%$ & $0,4045 \%$ & $79,91 \%$ \\
\hline c5 & $35.951,66$ & $10.844,79$ & $0,10894 \%$ & $0,0125 \%$ & $88,56 \%$ \\
\hline c6 & $297.315,48$ & $60.040,04$ & $0,90096 \%$ & $0,0690 \%$ & $92,34 \%$ \\
\hline c7 & $84.697,62$ & $20.490,65$ & $0,25666 \%$ & $0,0236 \%$ & $90,82 \%$ \\
\hline c8 & $86.947,76$ & $10.669,78$ & $0,26348 \%$ & $0,0123 \%$ & $95,35 \%$ \\
\hline c10 & $1.961 .756,78$ & $5.916 .585,65$ & $5,94472 \%$ & $6,8007 \%$ & $-14,40 \%$ \\
\hline c11 & $653.918,93$ & $493.048,80$ & $1,98157 \%$ & $0,5667 \%$ & $71,40 \%$ \\
\hline Total & $3.979 .596,99$ & $6.933 .165,58$ & $12,05939 \%$ & $7,9692 \%$ & $33,92 \%$ \\
\hline
\end{tabular}

Fonte: Elaborada pelo autor com dados da pesquisa

Não foi possível calcular a variação dos riscos a1, a2 e c9, pois antes da implantação tais procedimentos não eram realizados. Observa-se uma redução substancial em praticamente todos os riscos tributários, exceção feita ao risco c10, que foi classificado pela Empresa A como de baixa probabilidade de se transformar em multa tributária. Mesmo possuindo o maior valor (risco c 10), ainda assim houve uma redução de 33,92\% no total dos riscos tributários. Ressaltese que esta percepção mudou a partir de 2011, conforme discorrido anteriormente. 
O consultor tributário afirmou que o desenvolvimento de sistema próprio, visando à satisfação total das informações a serem apresentadas ao Fisco através do SPED, deverá, em tese, eliminar as inconsistências dos arquivos digitais SINTEGRA (risco c10), assim como o dos livros fiscais (risco c11) e as inconsistências das declarações tributárias (risco c12). Ressalta também que, atualmente, o risco c3 deve-se majoritariamente a riscos do ambiente externo, mais especificamente, o dolo do fornecedor do que propriamente a ocorrência de algum fator de risco interno.

Calculou-se também o valor presente do VaR dos riscos tributários, considerando como horizonte temporal a perpetuidade, conforme Tabela 8 .

Tabela 8: Valor presente do VaR dos riscos tributários - exercício de 2010

\begin{tabular}{|c|c|c|c|c|}
\hline Risco & Valor do VaR & Prob/ Ocorr & VaR x (Prob/Ocorr) & Valor presente do VaR \\
\hline c1 & $21.723,41$ & $24 / 15248$ & 34,19 & 264,44 \\
\hline c2 & $43.477,67$ & $6 / 1338$ & 194,97 & $1.507,87$ \\
\hline c3 & $464.517,61$ & $7 / 367$ & $8.860,01$ & $68.522,88$ \\
\hline c5 & $11.500,06$ & $120 / 33650$ & 41,01 & 317,17 \\
\hline c6 & $68.076,33$ & $72 / 33650$ & 145,66 & $1.126,54$ \\
\hline c7 & $4.084,76$ & $960 / 33650$ & 116,53 & 901,27 \\
\hline c8 & $18.813,73$ & $30 / 15248$ & 37,02 & 286,28 \\
\hline c10 & $369.237,88$ & $12 / 12$ & $369.237,88$ & $2.855 .668,06$ \\
\hline c11 & $269.966,27$ & $6 / 36$ & $44.994,38$ & $347.984,37$ \\
\hline & $\mathbf{1 . 2 7 1 . 3 9 7 , 7 2}$ & & $\mathbf{4 1 4 . 2 3 2 , 2 6}$ & $\mathbf{3 . 2 0 3 . 6 5 2 , 4 2}$ \\
\hline
\end{tabular}

Fonte: Elaborado pelo autor com dados da pesquisa

Percebe-se que, embora o valor presente do VaR seja inferior à média aritmética ponderada, tais valores não podem ser ignorados, pois o lucro líquido do exercício de 2010 foi de aproximadamente $\mathrm{R} \$ 2.000 .000,00$.

As observações colhidas no estudo de caso apontam para a seguinte avaliação preliminar de pontos fortes e fracos do método quantitativo:

\section{Pontos fortes}

- permite a mensuração econômica de alguns riscos tributários;

- reduz consideravelmente a subjetividade na classificação dos riscos tributários.

\section{Pontos fracos}

- necessidade de auditoria interna/externa, pois algumas irregularidades apenas tornam-se riscos tributários se resultarem em falta de pagamento de ICMS;

- a mensuração do valor em risco considera como certa a sua materialização em multa tributária, o que apenas ocorrerá se a empresa passar por uma auditoria tributária por parte do Fisco, e este constatar a irregularidade;

- não permite considerar a percepção da empresa em relação à provável materialização do risco tributário em multa;

- não capta a realidade social através de suas inferências;

- não permite compreender a relação entre os fatores de risco, o risco e as respostas selecionadas para minimizá-lo. 


\section{CONSIDERAÇÕES FINAIS}

Este estudo foi conduzido com o propósito de identificar, empiricamente, os fatores que afetam os riscos de conformidade tributária. Para tanto, foi utilizada a metodologia de estudo de caso em uma empresa do ramo industrial, que implantou uma política de gerenciamento de riscos tributários em 2003.

Investigou-se no caso a forma como eram realizados os processos e procedimentos relacionados à tributação, especificamente do ICMS do Estado de São Paulo; como eram realizados anteriormente à implantação da política de gerenciamento de resultados; quais as mudanças implementadas; os riscos reduzidos e qual a percepção da empresa em relação à probabilidade e impacto de cada risco. Para a realização desta tarefa, utilizou-se a metodologia sugerida em COSO (2004b) para a identificação e avaliação dos riscos tributários, assim como as atividades de controle e de resposta aos riscos e, ainda, as de monitoramento.

Houve uma redução média geral de 33,92\% nos riscos tributários após a implantação do gerenciamento. Em relação à avaliação dos riscos, os resultados da pesquisa indicam que, apesar de a literatura afirmar que o impacto financeiro no resultado ser a própria expressão do grau de risco, a probabilidade da materialização do risco tributário em multa foi considerada pela empresa como o fator preponderante, ao invés do impacto em seu resultado.

Assim, embora a racionalidade indique que o impacto do fator de risco define o grau de risco, o estudo mostra um indício de que a aversão ao risco em decorrência da não conformidade tributária pode induzir o agente a considerar a probabilidade de materialização do risco tributário em multa como a variável que define o seu grau de risco.Percebeu-se que a aversão ao risco refere-se principalmente à probabilidade de ser fiscalizado, e não exatamente ao impacto dos riscos tributários a que a empresa está exposta.

Dos modelos de mensuração de risco desenvolvidos e utilizados neste estudo, foi possível verificar que a análise qualitativa possui como pontos positivos: a possibilidade de se avaliar todos os riscos identificados sem a realização de uma auditoria interna/externa, a despeito da considerável carga de subjetividade; compreender a influência dos fatores de risco nas atividades relacionadas com a tributação, de forma aprofundada e detalhada, possibilitando percebê-los dentro da realidade da empresa e incrementando o entendimento dos casos e situações detalhadas; possibilita considerar a percepção da empresa em relação ao grau de materialização do risco tributário em multa. Entretanto a classificação das variáveis depende da subjetividade do pesquisador e do entrevistado, além de não possibilitar a mensuração econômica dos riscos tributários.

A análise quantitativa elimina boa parte da subjetividade, além de permitir a mensuração econômica de alguns riscos tributários. Entretanto, não foi possível realizar a avaliação de todos os riscos tributários identificados, pois alguns destes somente são tipificados como infração à legislação tributária paulista quando resulta na falta de pagamento do ICMS devido de forma indireta, o que leva à necessidade de realização de auditoria interna/externa.

Também não permite ao pesquisador captar a realidade social, considerar a percepção da empresa em relação à provável materialização do risco tributário em multa, tampouco compreender a relação entre os fatores de risco, o risco e as respostas selecionadas.

Para o gerenciamento de riscos tributários, em relação aos modelos desenvolvidos e 
utilizados neste estudo, os resultados sugerem que a avaliação qualitativa permite a obtenção de informações mais completas em relação aos fatores de risco e às suas características, imprescindível para a compreensão do risco e uma correta mensuração, ao passo que a avaliação quantitativa permite apenas a mensuração econômica de alguns dos riscos tributários, sem considerar outros fatores inerentes aos riscos.

A utilização de estudo de caso, dentro deste contexto específico, não permite a generalização de seus resultados.

\section{REFERÊNCIAS}

ALMEIDA, M. C. Auditoria: um curso moderno e completo. 5. Ed. São Paulo: Atlas, 1996.

BARALDI, P. Gerenciamento de riscos empresariais. 3. ed. Rio de Janeiro: Elsevier, 2010.

BERTOLUCCI, A. V. Uma contribuição ao estudo da incidência dos custos de conformidade às leis e disposições tributárias: um panorama mundial e pesquisa dos custos das companhias de capital aberto no Brasil. 2001. Dissertação (Mestrado em Controladoria e Contabilidade) - Faculdade de Economia, Administração e Contabilidade da Universidade de São Paulo, São Paulo, 2001.

COMMITTEE OF SPONSORING ORGANIZATIONS OF THE TREADWAY COMISSION - COSO. Enterprise Risk Management. Integrated Framework - Executive Summary Framework. Durham: AICPA, 2004a.

. Enterprise Risk Management. Integraded Framework - Application Techniques. Durham: AICPA, 2004b.

CROUHY, M; GALAI, D; MARK, R. Gerenciamento de Risco: Abordagem conceitual e prática: Uma visão integrada dos riscos de crédito, operacional e de mercado. São Paulo: SERASA, 2004.

DAS-GUPTA A. Income Tax Compliance Cost of Corporations in India, 2000-01. Vikalpa, Ahmedabad, v. 31, n. 4, out/dez 2006.

ERNST \& YOUNG. Steady Course, Uncharted Waters - Findings from the third Ernst \& Young global tax risk survey. London: EYGM, 2008. Disponível em: $<$ www2.eycom. ch/.../200812_ey_global_tax_risk_survey_findings.pdf> Acesso em: 01 jul. 2011.

EVANS, C. The operating costs of taxation: a review of the research. Economic Affairs, Malden, v. 21, n. 2, p. 5-9, 2001.

; TRAN-NAM, B. Evaluating the compliance costs and benefits of the Tax Value Method: A report prepared for the Board of Taxation. Canberra, 2002.

FABRETTI, L. C. Contabilidade Tributária. 11. ed. São Paulo: Atlas, 2009.

GODWIN, M. Compliance Costs - The Cost of Paying Tax. Omega, [S.1.], v. 6, n. 5, p. 389398, 1978. 
GOODMAN, G. R. Internal controls for the tax department. Tax Notes, [S.1.], v. 103, n. 5, 2004.

IUDÍCIBUS, S. Teoria da Contabilidade. 9. ed. São Paulo: Atlas, 2009.

JORION, P. Value at Risk: A nova fonte de referência para o controle do risco de Mercado. 1. ed. 5. reimp. São Paulo: Bolsa de Mercadorias \& Futuros, 1999.

KAPLOW, L. How tax complexity and enforcement affect the equity and efficiency of the income tax. National Tax Journal, Washington, v. 49, n. 1, 1996.

KOPEZUK, W. Tax simplification and tax compliance: An economic persepective. In: SAWICKY, M. B. (Ed.). Bridging the Tax Gap. Washington D. C.: Economic Policy Institute Book, 2006.

MARTINEZ, A. L. Agency Thory na Pesquisa Contábil. In: ENCONTREO DA ANPAD ENANPAD 1998, 22. Foz do Iguaçu. Anais... Foz do Iguaçu: ANPAD, 1998.

MERCHANT, K. A.; OTLEY, D. T. A review of the literature on control and accountability.

Handbook of Management Accounting Research, [S.1.], v. 2, p. 785-802, 2007.

NEUBIG, T.; SANGHA, V. Tax risk and strong corporate governance. Tax Executive, Washington, v. 56, n. 2, p. 114-119, 2004.

OLIVEIRA, M. T. A importância da contabilidade no processo de decisão entre lucro real e lucro presumido. 2009. Dissertação (Mestrado em Controladoria e Contabilidade) - Faculdade de Economia, Administração e Contabilidade da Universidade de São Paulo, São Paulo, 2009.

PAULO, W. L.; FERNANDES, F. C.; RODRIGUES, L. G. B.; EIDIT J. Riscos e controles internos: uma metodologia de mensuração dos níveis de controle de riscos empresariais. Revista Contabilidade \& Finanças, São Paulo, v. 18, n. 43, 2007.

PENHA, J. C.; PARISI, C. Um caminho para integrar a gestão de riscos à controladoria. In:

CONGRESSO INTERNACIONAL DE CUSTOS, 2005, Itapema/SC. São Leopolodo Anais... São Leopolodo: ABC, 2005.

POPE, J. The Compliance Cost of Taxation in Australia and Tax Simplification: The Issues. Australian Journal of Management, Sydney, v. 18, n. 1, p. 69-89, 1993.

POWER, M. The risk management of nothing. Accounting, Organizations and Society, [S.1.], v. 34, p. 849-855, 2009.

REINGANUM, J. F.; WILDE, L. L. Income Tax Compliance in a Principal-Agent Framework. Journal of Public Economics, Amsterdam, v. 26, 1985.

RICCIO, E. et al. Introdução ao XBRL - nova linguagem para a divulgação de informações empresariais pela internet. Revista Ciência da Informação, Brasília, v. 35, n. 3, p. 166-182, set/dez 2006.

SAITO, R.; SILVEIRA, A. D. M. Governança Corporativa: custos de agência e estrutura de 
propriedade. Revista de Administração de Empresas, São Paulo, v. 48, n. 2, p.79-86, 2008.

SANDFORD, C.; GODWIN, M.; HARDWICK, P. Administrative and Compliance Costs of Taxation. Bath: Fiscal Publications, 1989.

SLEMROD, J.; BLUMENTHAL, M. The income tax compliance cost of big business. Public Finance Quarterly, v. 24, n. 4, p. 411-438, out. 1996.

; VENKATESH, V. The Income Tax Compliance Cost of Large and Mid-size Business: A Report to the IRS LMSB Division. Ann Arbor, 2002.

SPIRA, L. F.; PAGE, M. J. Risk Management: The Reinvention of Internal Control and the Changing Role of Internal Audit. Accounting, Auditing and Accountability Journal, Londres: v. 16, n. 4, p. 640-661, 2003.

STONEBURNER, G.; GOGUEN, A.; FERINGA, A. Risk Management guide for Information Technology Systems: Recommendations of the National Institute of Standards ad Technology. Washington, 2001.

SVENSSON, G. Key areas, causes and contingency planning of corporate vulnerability in supply chains - A qualitative approach. International Journal of Physical Distribution \& Logistics Management, v. 67, n. 9, p. 728-748, 2004.

TRAN-NAM, B.; EVANS, C.; WALPOLE, M.; RITCHIE, K. Tax Compliance Costs: Research Methodology and Empirical Evidence from Australia. National Tax Journal, Washington, v. 53, n. 2, p. 229-252, 2000.

WUNDER, H.F. Tax risk management and the multinational enterprise. Journal of International Accounting, Auditing and Taxation, v. 18, p. 14-28, 2009. 


\section{ENDEREÇO DOS AUTORES}

\section{Roberto Kazuo Miyoshi}

Secretaria da Fazenda do Estado de São Paulo

Av. Presidente Kennedy, 1.550

14.096-340 - Ribeirão Preto - SP - Brasil

\section{Sílvio Hiroshi Nakao}

Faculdade de Economia, Administração e Contabilidade de Ribeirão Preto da Universidade de São Paulo

Endereço Av. Bandeirantes, 3900

14.040-900 - Ribeirão Preto - SP - Brasil 